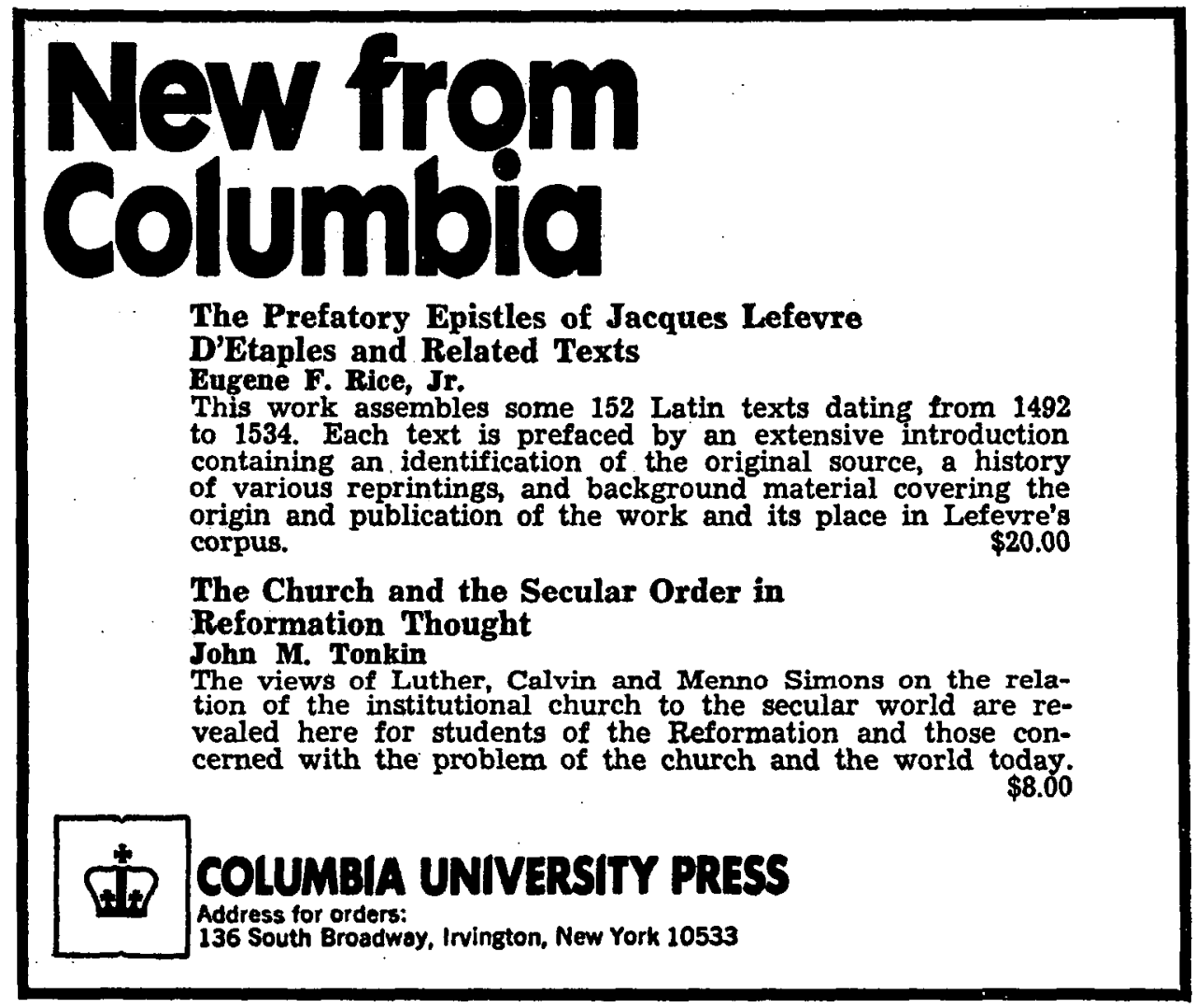

New

\title{
The Lands of St. Peter
}

The Papal State in the Middle Ages

and the Early Renaissance

Peter Partner

In this first continuous history of the Papal State since Gregorovius's classic, Mr. Partner details the vicissitudes of the secular power of the Papacy from the reign of Gregory I up to the Great Schism. He brings out the local nature of the political objectives of the popes and emphasizes the continuity of the territorial factors in papal policy.

LC: $73-182793494$ pages 16 pages of plates 6 maps $\$ 17.50$

\section{The Heresy of the}

\section{Free Spirit in the Later Middle Ages}

\section{Robert E. Lerner}

Most historians, relying on hostile sources of the 14th century, have described the Free Spirit heretics as a league of anarchical deviants who preached sexual license and subversion of authority. In this study the author uses inquisitorial and polemical sources plus testimony of Free Spirits themselves to conclude that there was no tightly organized Free Spirit sect, and that those who may be called Free Spirits were passive mystics who neither practiced nor preached subversion or libertinism.

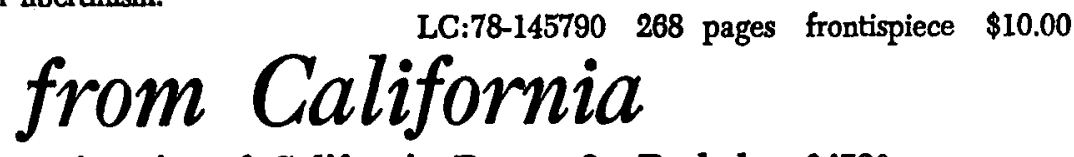

University of California Press - Berkeley 94720 